DOE/NASA/20320-32

NASA TM-82653

RETURN TO LIBRARY

\title{
Tests of an Overrunning Clutch in a Wind Turbine
}

Robert C. Seidel and Henry G. Pfanner

National Aeronautics and Space Administration Lewis Research Center

July 1981

BOEING TECHNICAL LIBRARY

ST. LOUIS

MAILCODE:

$1+1025$

$5250-1200$

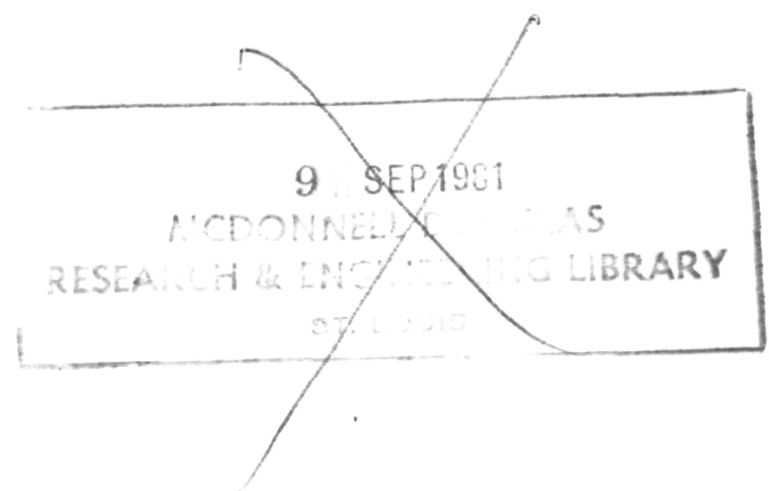

Prepared for

U.S. DEPARTMENT OF ENERGY

Conservation and Renewable Energy

Division of Wind Energy Systems 


\section{NOTICE}

This report was prepared to document work sponsored by the United States Government. Neither the United States nor its agent, the United States Department of Energy, nor any Federal employees, nor any of their contractors, subcontractors or their employees, makes any warranty, express or implied. or assumes any legal liability or responsibility for the accuracy, completeness, or usefulness of any information. apparatus, product or process disclosed. or represents that its use would not infringe privately owned rights. 
DOE/NASA/20320-32

NASA TM-82653

\section{Tests of an Overrunning Clutch in a Wind Turbine}

Robert C. Seidel and Henry G. Pfanner

National Aeronautics and Space Administration

Lewis Research Center

Cleveland, Ohio 44135

July 1981

Work performed for

U.S. DEPARTMENT OF ENERGY

Conservation and Renewable Energy

Division of Wind Energy Systems

Washington, D.C. 20545

Under Interagency Agreement DE-Al01-76ET20320 
TESTS OF AN OVERRUNNING CLUTCH IN A WIND TURBINE

by Robert C. Seidel and Henry G. Pfanner

Summary

The report describes the tests that were run on an overrunning clutch, a concept being considered for use on advanced wind turbine designs. The overrunning clutch has potential to simplify operations and improve wind turbine performance in low and variable winds. The energy capture can be increased because, as the wind decreases, the wind turbine does not motor but is permitted to coast below synchronous speed. Also, as the wind speed increases, the rotor rpm increases to synchronous and produces power without requiring time for wind speed averaging or synchronization. The overrunning clutch was installed between the gearbox and the alternator. Overrunning clutches are mature mechanical devices made by a number of manufacturers and have rated life cycles consistent with a thirty year wind turbine life. The test traces show that the clutch engages and uncouples with essentially no power perturbation or oscillation. When the alternator is disconnected from the wind turbine rotor, the effective motoring inertia is about ten times less and synchronization is easier. In tests, the alternator was closed to the line from under speed rather than at the precise synchronous speed.

\section{Int roduction}

The Mod-0 $100 \mathrm{~kW}$ Experimental Wind Turbine located near Sandusky, Ohio serves as a testbed for the Federal Large Horizontal Axis Wind Turbine Program and is used to evaluate new design concepts prior to their use in large wind turbine designs. The machine was designed and fabricated and has been utilized for advanced technology experiments by the NASA Lewis Research Center as part of the overall Federal Wind Program managed by the U.S. Department of Energy. One of the uses of this wind turbine is to evaluate new design concepts prior to their use in large wind turbine designs. This report describes the tests that were run on an overrunning clutch, which is a concept being considered for use on advanced wind turbine designs.

The overrunning clutch has potential to simplify operations and improve wind turbine performance in low and variable winds. In the design concept, a standard industrial overrunning clutch is installed in the high speed drive train between the gear box and the alternator. Anytime the output rpm of the gear box drops below synchronous rpm the clutch will disengage permitting the alternator to run at synchronous rpm as a no load motor. The wind turbine rotor $\mathrm{rpm}$ is then free to vary with wind speed until the rotor speed attempts to exceed synchronous rpm. At that time the clutch will engage and the wind turbine will begin to drive the generator. No control operations are required during this sequence of events. 
Operation with an overrunning clutch has several potential advantages. An automatic synchronizer is not required because the generator $c$ an be connected to the line when the rpm is within a few percent of synchronous and it will motor to synchronous speed. The control system can be simplified because, in low variable winds, the generator is not disconnected from the line and the wind turbine is not shutdown. The energy capture can be increased because the wind turbine does not motor in low wind but is permitted to coast below synchronous speed. Also, as the wind speed increases, the rotor $\mathrm{rpm}$ increases to synchronous and produces power without requiring time for start-up and synchronization. The lifetime of the electrical switchgear is increased because the number of electrical connects and disconnects is reduced. The lifetime of the blades may also be increased when the motoring, shutdown, and start-up cycles are reduced. The overrunning clutch also has potential advantages for a two speed wind turbine because it may enable speed changes to be made faster and with fewer control manipulations.

This report describes the results of tests of the overrunning clutch on the Mod- 0 wind turbine. The operation of the wind turbine with and without an overrunning, clutch are compared and the potential advantages are examined.

\section{Wind Turbine Configuration}

An overall view of the Mod-0, 125 foot diameter wind turbine used in the tests is shown in figure 1. The Mod-0 was in the teetered-hub, tip-control configuration described in reference 1 . The turbine blades have zero twist and the inboard seventy percent of the blades is fixed at zero degrees pitch. Servo controls vary the pitch angles of the tip section to control rotor power or $\mathrm{rpm}$. The yaw drive aligns the turbine axis with the wind.

The elements of the power train are shown in figure 2. During the tests the turbine speed was $31.3 \mathrm{rpm}$ for synchronous alternator operation. The overrunning clutch was installed between the gearbox and the belt drive on a shaft rotating at $1420 \mathrm{rpm}$. A fluid coupling filled to slip about 4 percent at $100 \mathrm{~kW}$ is shown on the same shaft. However, tests were run with and without the fluid coupling. A belt drive increased the speed of the drive train to $1800 \mathrm{rpm}$ at the alternator.

\section{Description of the Overrunning Clutch}

A schematic of a cam type overrunning clutch is shown in Figure 3 to illustrate the principle of operation. An overrunning clutch transmits torque in one direction and slips freely in the other. It is a passive device with no active controls. Overrunning clutches, also referred to as one way, freewheeling, or backstop clutches, are mature mechanical devices made by a number of manufacturers (ref. 2). A view of the overrunning clutch on the Mod- 0 high speed shaft is shown in figure 4. This overrunning clutch is rated at $600 \mathrm{ft}-1 \mathrm{~b}$ ( $153 \mathrm{~kW}$ at $1800 \mathrm{rpm}$ ), 
measures less than six inches in diameter and four inches long, and costs about \$400. The advertised life of the clutch appears to be consistent with a thirty year wind turbine life. The clutch is designed for tens of millions of on-off, zero to full load, cycles which is more than the number expected on a large wind turbine. In the extreme case of zero turbine speed and full $1800 \mathrm{rpm}$ alternator speed, the clutch could overrun continuously for about three years or $10 \%$ of the wind turbine operating life. The life in the overrunning mode is increased to about six years if the turbine were turning at two-thirds the operational speed or one-third slip. Most of the overrunning on the wind turbine will occur with less than one-third slip and therefore the design 1 ife in the overrunning mode should exceed wind turbine requirements.

\section{Description of Operation With and Without an Overrunning Clutch}

The potential advantages of the overrunning clutch occur during wind turbine start-up, shut-down, operation in low variable winds, and changing speeds in a two speed wind turbine. The potential advantages will be illustrated by describing and comparing the current method of operation with the proposed operation with an overrunning clutch.

\section{Control Without the Clutch}

The $200 \mathrm{~kW}$ Mod-OA wind turbine will be used to illustrate operation without a clutch. The Mod-OA wind turbine is controlled by a microprocessor computer control system which initially operated as follows :

The control system senses wind speed and makes decisions based on a one minute running average. If the wind speed average drops below $10 \mathrm{mph}$ and the turbine is operating, the control system initiates shutdown by disconnecting the alternator from the line and stopping the rotor with the pitch control. When the wind turbine is shut down and the wind speed average rises above $12 \mathrm{mph}$ the control attempts a restart. The Clayton, New Mexico Mod-OA WT initially experienced about twelve start-up/shutdown cycles per day with a resulting energy loss of about 5 percent.

The typical time required for the shutdown/start-up cycle was as follows. The low wind speed averaging process allows the wind turbine to motor for one minute before starting the shutdown. The time to halt all turbine rotation (by slowly feathering the blades) is about 1.5 minutes. After a one-minute delay the control restarts when the wind speed average exceeds $12 \mathrm{mph}$. The time to return to rated speed (with the pitch system in speed control) is 2 to 10 minutes depending on the wind speed. To obtain the precise speed and phase for closure by the automatic synchronizer requires another one to two minutes. Based on the initial control system design, the time to restart ranges from 4 to 13 minutes and the total time for the shutdown/startup cycle ranges from 6 to 14 minutes. 


\section{Control With The Over-Running Clutch}

The use of the overrunning clutch eliminates the need for wind speed averaging, disconnect and connect to the line, and pitch control to regulate rpm after disconnect and during the synchronization period. As the wind speed decreases the generator power will decrease. When the generator power reaches zero the clutch will begin to slip and the wind turbine rotor will continue to slow down with wind speed while the alternator remains connected to the line running as a no load motor. The control system remains in the power control mode with the blades pitched to full power and when the wind speed increases the rotor rpm is free to increase until synchronous $\mathrm{rpm}$ is reached. If the wind turbine tries to exceed synchronous rpm the cams of the clutch engage and the alternator begins to produce power. If low winds persist the wind turbine will be shut down and the alternator disconnected from the line.

\section{Over-Running Clutch Test Results}

The overrunning clutch test was run to help answer several questions. Would the clutch engage and disengage smoothly in low variable winds? Would the clutch cause power perturbations or dynamic oscillations when it engaged? Is the fluid coupling necessary for smooth stable operation? What are the motoring losses when the coupling is free wheeling? Could initial synchronizations be made without an automatic synchronizer without significant electrical transients? Could the wind turbine using the overrunning clutch be started-up and synchronized with fixed pitch blades?

\section{Operation in Low and Variable Winds}

Data traces of operations in low and variable winds are shown in figure 5 . In the twenty minutes of data shown, the clutch overran more than five times. In only two times did the turbine rpm drop much below the rated speed of $31.3 \mathrm{rpm}$, illustrating the difficulty an active control would have in correctly deciding when to shut down and restart. In these periods, the active control might have shut the machine down unnecessarily. The trace shows that the clutch engages and uncouples with essentially no power perturbation or oscillation.

With the clutch, the alternator motored with about a $7 \mathrm{~kW}$ power loss. A $2 \mathrm{~kW}$ loss was due to the generation of 60 kilovars reactive power. With a lower level of alternator excitation, the power loss was $5 \mathrm{~kW}$. Because of the location of the clutch in the drive train, the alternator still motors the belt drive and fluid coupling when the clutch is overrunning. If the clutch were mounted directly on the alternator the losses in these components would be avoided and the idle power would be less than $5 \mathrm{~kW}$. This compares to an idle power loss of up to $50 \mathrm{~kW}$ for a 125 foot rotor at $40 \mathrm{rpm}$ without the overrunning clutch. 
When the alternator is not connected to the wind turbine rotor, the effective motoring inertia is about ten times less and synchronization is easier. In tests, the alternator was connected to the line from under speed rather than at the precise synchronous speed. The moment of closure was determined by a simple mechanical relay instead of an automatic synchronizer. The relay spring tension was set to permit closures when the alternator-to-line voltage corresponded to a phase error of forty-five degrees or less. The transient resulting from an intentional closure from about five percent under synchronous speed is shown in figure 6 . The alternator was motored to synchronous speed in about 0.15 seconds with a momentary peak power consumption of $50 \mathrm{~kW}$. The short duration peak power observed is not a problem. On a production wind turbine, the system microprocessor could replace the relay.

Tests were run without a fluid coupling in the drive train and the results are shown in figure 7 . This data shows that the fluid coupling is not required for synchronization as the same type of power peaks were observed with and without it. The simplified closure also worked from a slight overspeed.

Tests were run to demonstrate that the wind turbine could be synchronized without pitch controls. These tests simulated operation with fixed pitch blades. A typical yaw start is shown in figure 8 . The wind turbine was started by yawing the rotor $60^{\circ}$ to the wind releasing the yaw brake and then yawing the rotor further out of the wind to control the rpm. The rpm increased and as the rpm neared 31, the alternator was connected to the grid by the relay. A yaw start test is shown in figure 8 .

\section{Concluding Remarks}

An overrunning clutch that slipped freely under reverse torque was tested in the drive train of the Mod-0 wind turbine. In low and variable wind conditions the clutch engaged and disengaged smoothly without power perturbations or oscillations. The clutch permitted the generator to be connected to the line using a relay instead of an automatic synchronizer. The alternator was connected to the line when the rpm reached $95 \%$ of synchronous speed and it motored to synchronous speed in about 0.15 seconds with a momentary power spike of $50 \mathrm{~kW}$. The performance of the overrunning clutch was the same with and without the fluid coupling. The idle power with the clutch was 5 to $7 \mathrm{KW}$ compared to up to $50 \mathrm{~kW}$ without the clutch. The overrunning clutch performed well on the Mod-O and merits consideration in future wind turbine designs as a means of simplifying the control system, increasing energy capture, and increasing the life of blades and electrical switch gear. 
References

1. Glasgow, J. C., and Miller, D. R.: Teetered, Tip-Controlled Rotor: Preliminary Test Results from Mod-0 100-kW Experimental Wind Turbine. NASA TM-81445, 1980.

2. Morse Overrunning Clutch. Morse Chain, Division of Borg-Warner Corporation Ithaca, New York. Form 4146-002, Model M-600, Rev. Nov. 1969.

3. Gnecco, A. J.; and Whitehead, G. T.: Microprocessor Control of a Wind Turbine Generator. NASA TM-79021, 1978.

4. Spera, D. A.: Structural Analysis Considerations for Wind Turbine Blades. Large Wind Turbine Design Characteristics and $\mathrm{R}$ and $\mathrm{D}$ Requirements, NASA CP-2106, CONF-7904111, 1979, pp. 211-224. 

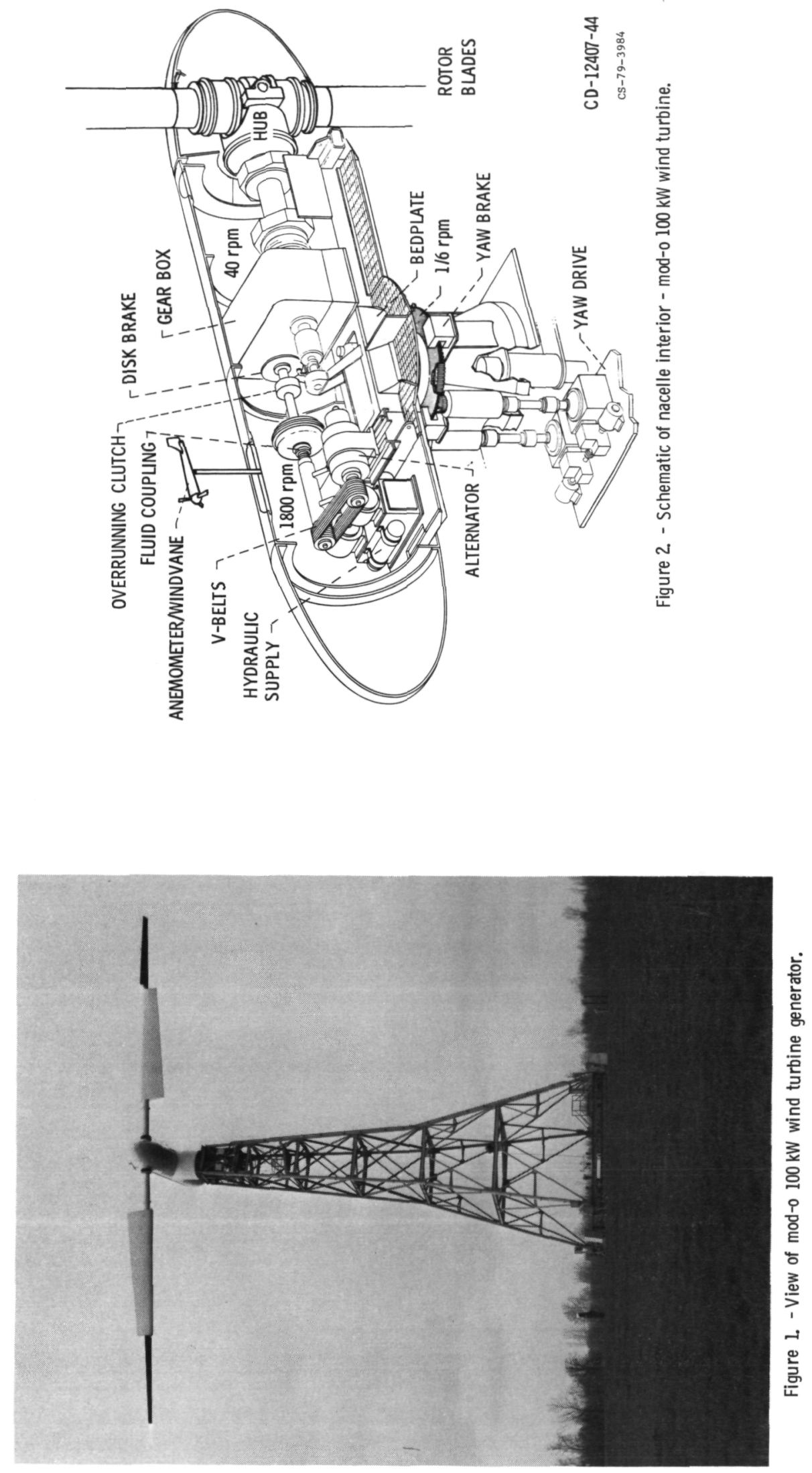

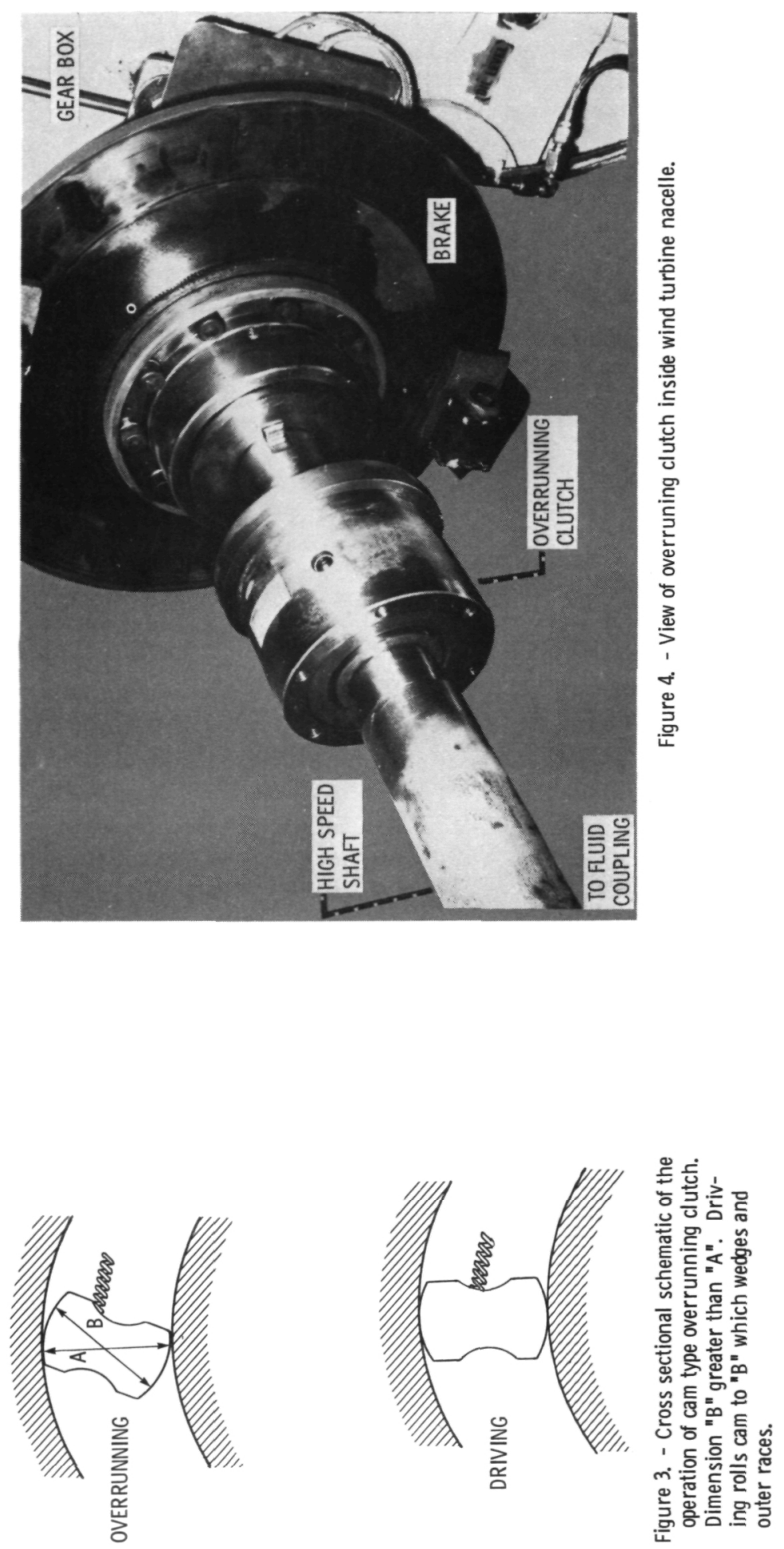

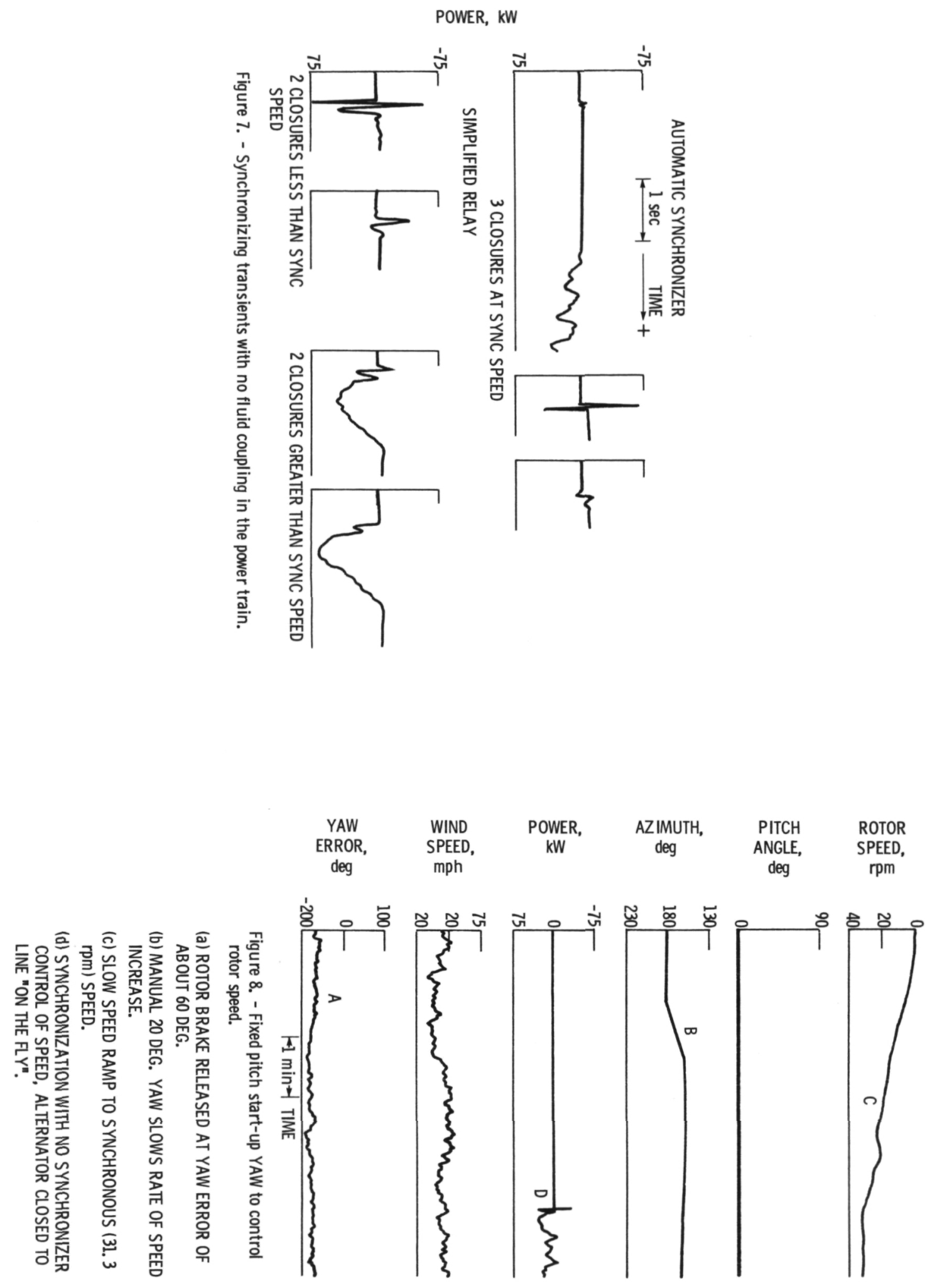

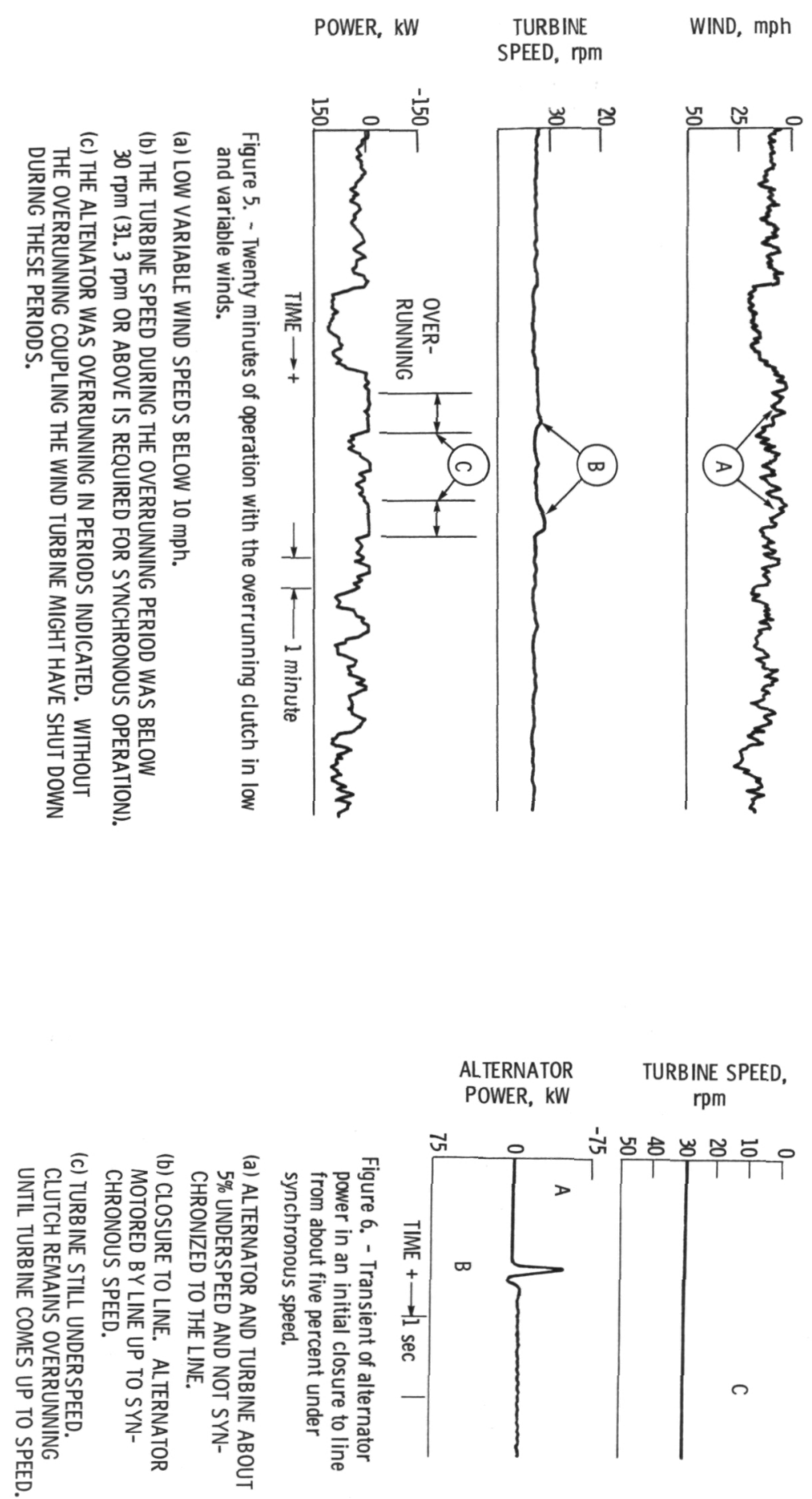


\begin{tabular}{|c|c|c|}
\hline $\begin{array}{l}\text { 1. Report No. } \\
\text { NASA TM- } 82653\end{array}$ & 2. Government Accession No. & 3. Recipient's Catalog No. \\
\hline \multirow{2}{*}{\multicolumn{2}{|c|}{$\begin{array}{l}\text { 4. Title and Subtitle } \\
\text { TESTS OF AN OVERRUNNING CLUTCH IN A WIND TURBINE }\end{array}$}} & $\begin{array}{l}\text { 5. Report Date } \\
\text { July } 1981 \\
\end{array}$ \\
\hline & & $\begin{array}{l}\text { 6. Performing Organization Code } \\
776-33-41\end{array}$ \\
\hline \multicolumn{2}{|c|}{$\begin{array}{l}\text { 7. Author(s) } \\
\text { Robert C. Seidel and Henry G. Pfanner }\end{array}$} & $\begin{array}{l}\text { 8. Performing Organization Report No. } \\
\text { E-914 }\end{array}$ \\
\hline \multirow{3}{*}{\multicolumn{2}{|c|}{$\begin{array}{l}\text { 9. Performing Organization Name and Address } \\
\text { National Aeronautics and Space Administration } \\
\text { Lewis Research Center } \\
\text { Cleveland, Ohio } 44135\end{array}$}} & 10. Work Unit No. \\
\hline & & 11. Contract or Grant No. \\
\hline & & \multirow{2}{*}{$\begin{array}{l}\text { 13. Type of Report and Period Covered } \\
\text { Technical Memorandum }\end{array}$} \\
\hline \multirow{2}{*}{\multicolumn{2}{|c|}{$\begin{array}{l}\text { 12. Sponsoring Agency Name and Address } \\
\text { U.S. Department of Energy } \\
\text { Division of Wind Energy Systems } \\
\text { Washington, D.C. } 20545\end{array}$}} & \\
\hline & & $\begin{array}{l}\text { 14. Sponsoring Agency Cede Report No. } \\
\text { DOE/NASA/20320-32 }\end{array}$ \\
\hline
\end{tabular}

15. Supplementary Notes

Final report. Prepared under Interagency Agreement DE-AI01-76ET20320.

16. Abstract

This report describes tests that were run on an overrunning clutch, a device being considered for use on advanced wind turbine designs. The overrunning clutch, sometimes called a freewheeling clutch, is a device which when added to the drive train will permit the rotor speed to drop below synchronous speed without taking the alternator off line. It has potential to simplify operations and improve performance in low and variable winds. The energy capture can be increased by allowing the rotor speed to decrease as the wind speed dips below cut-in wind speed for short periods. During these short periods, the generator remains synchronized and does not drive the rotor. As the wind speed increases, the rotor speed increases to synchronous speed and produces power without requiring time for resynchronizing the wind turbine. The overrunning clutch also simplifies the synchronization process and has application to 2 speed wind turbine operation.

\begin{tabular}{|c|c|c|c|c|}
\hline $\begin{array}{l}\text { 17. Key Words (Suggested by Author(s)) } \\
\text { Overrunning clutch } \\
\text { Wind turbine } \\
\text { Power train }\end{array}$ & & \multicolumn{3}{|c|}{$\begin{array}{l}\text { 18. Distribution Statement } \\
\text { Unclassified - unlimited } \\
\text { SंTAR Category } 44 \\
\text { DOE Category UC-60 }\end{array}$} \\
\hline $\begin{array}{l}\text { 19. Security Classif. (of this report) } \\
\text { Unclassified }\end{array}$ & 20. Securit & $\begin{array}{l}\text { f this page) } \\
\text { ssified }\end{array}$ & 21. No. of Pages & 22. Price ${ }^{*}$ \\
\hline
\end{tabular}

* For sale by the National Technical Information Service, Springfield, Virginia 22161 